\title{
Diurnal variation of summer precipitation over the Tibetan Plateau: a cloud-resolving simulation
}

\author{
Jianyu Xu' ${ }^{1}$, Bing Zhang ${ }^{1}$, Minghuan Wang ${ }^{1}$, and Huijuan Wang ${ }^{2}$ \\ ${ }^{1}$ Wuhan Institute of Heavy Rain, China Meteorological Administration, Wuhan, China \\ ${ }^{2}$ Weather Modification Office of Hubei Province, Wuhan, China
}

Correspondence to: Jianyu Xu (xujyster@gmail.com)

Received: 31 December 2011 - Revised: 6 September 2012 - Accepted: 15 October 2012 - Published: 8 November 2012

\begin{abstract}
In this study, the Weather Research and Forecasting model was used to simulate the diurnal variation in summer precipitation over the Tibetan Plateau (TP) at a cloudresolving scale. Compared with the TRMM, precipitation data shows that the model can well simulate the diurnal rainfall cycle with an overall late-afternoon maximum precipitation in the central TP and a nighttime maximum in the southern edge. The simulated diurnal variations in regional circulation and thermodynamics are in good correspondence with the precipitation diurnal cycles in the central and southern edge of TP, respectively. A possible mechanism responsible for the nocturnal precipitation maximum in the southern edge has been proposed, indicating the importance of the TP in regulating the regional circulation and precipitation.
\end{abstract}

Keywords. Meteorology and atmospheric dynamics (Precipitation)

\section{Introduction}

The Tibetan Plateau (TP) has crucial influences on the Asian monsoon climate and global climate system. In summer, the TP is a huge elevated heating source (Yanai et al., 1992) that exerts a significant effect on the atmospheric motion. Krishnamurti and Kishtawal (2000) have pointed out that continental-scale circulation changes can be observed in the upper troposphere over the TP in summer.

Numerous studies (e.g., Dai, 2001; Nesbitt and Zipser, 2003; Hirose and Nakamura, 2005) have demonstrated that summer precipitation over land regions has significant diurnal variation and usually reaches the maximum in the lateafternoon. However, topography, land-sea contrast, surface heterogeneity, convection propagation and other factors can cause different regions to have varying diurnal characteristics. In general, the diurnal variation in precipitation is closely related to the diurnal variation in circulation. However, there are relatively few studies on the diurnal variation in circulation (Chow and Chan, 2009). With its complex topography and substantial surface inhomogeneity, the TP may have unique diurnal variations in regional circulation and precipitation.

The pioneer numerical simulation of the diurnal cycle over the TP has been carried out by Kuo and Qian (1981) using a coarse resolution "dry" model (no precipitation) with only five vertical levels. Different physical fields are shown to have significant diurnal variations. Based on an evaluation of reanalysis data at 00:00 and 12:00 UTC, Yanai et al. (1992) as well as Yanai and Li (1994) have found that vertical motion, surface temperature and convection have significant diurnal variations over the TP in summer. The convective activity is strong at 12:00 UTC and weak at 00:00 UTC. Recent studies using field observations, radar data and satellite data have confirmed these results (e.g., Liu et al., 2002; Bhatt and Nakamura, 2005; Fujinami et al., 2005).

The very recent study of Liu et al. (2009) using the TRMM multi-satellite precipitation analysis product with high spatial and temporal resolutions reveal that summer rainfall over the TP has a significant diurnal variation. Summer rainfall is maximum in the late-afternoon/evening and predominantly minimum in the early morning. A notable exception is the prevalent nocturnal maximum around the periphery. Some studies have attempted to simulate rainfall over this region using regional climate models (e.g., Meinke et al., 2007; Rockel and Geyer, 2008), although the diurnal variability is not well simulated. Sato et al. (2008) have investigated the resolution dependency of the precipitation diurnal cycle over 


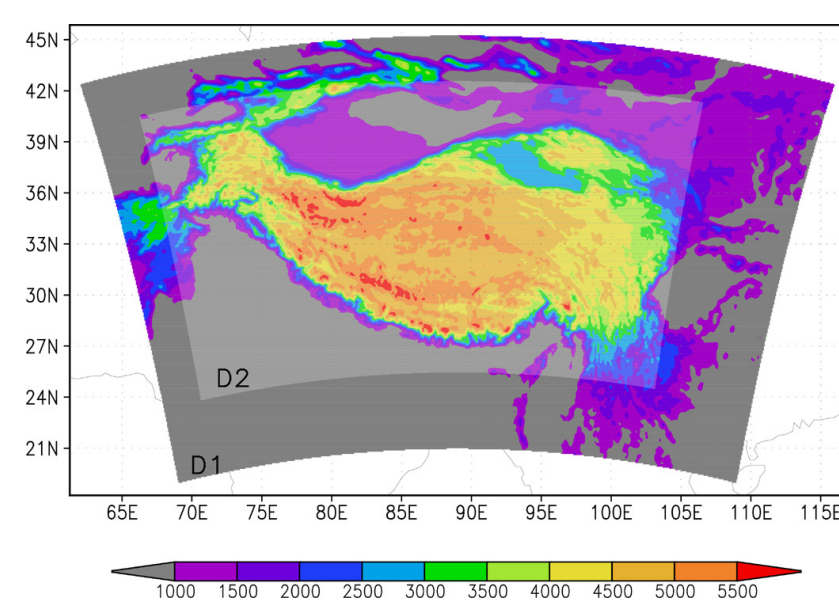

Fig. 1. Nested model domains and topography (m) of the simulation.

the TP in spring using a mesoscale model. They suggest that finer resolutions less than $7 \mathrm{~km}$ are necessary to simulate the realistic phase.

Based on the observations of Liu et al. (2009), the present study investigated the capability of a cloud-resolving model (CRM) in simulating the diurnal variation in summer precipitation over the TP. The high-resolution simulation by the CRM is used to explore the dynamics of the diurnal cycle in TP regions with complex topographies and heterogeneous land surfaces.

\section{Model and numerical simulation}

The Weather Research and Forecasting (WRF) model version 3.3 developed by the National Center for Atmospheric Research was used in the present study (Klemp et al., 2007). The WRF model is a fully compressible nonhydrostatic model, and uses the Arakawa $\mathrm{C}$ grid for horizontal and terrain-following hydrostatic-pressure vertical coordinates.

The configurations used in numerical simulation had two nested domains of 15 and $3 \mathrm{~km}$ grid spacings (Fig. 1). D1 had $288 \times 180$ grid points and D2 had $1101 \times 626$ grid points. The simulation used 31 vertical levels. The Rapid Radiative Transfer Model (RRTM) longwave radiation scheme (Mlawer et al., 1997), Dudhia shortwave radiation scheme (Dudhia, 1989), WRF Single-Moment 6-class (WSM6) microphysics scheme (Hong and Lim, 2006), and the Unified Noah Land Surface Model (Chen and Dudhia, 2001) were used for this simulation. The Kain-Fritsch (new Eta) (Kain, 2004) cumulus parameterization scheme was used in D1, and explicit convection was used in D2 (3 km resolution). The results from D2 were used for analysis.

The initial and boundary conditions were derived from $\mathrm{Na}-$ tional Centers for Environmental Prediction (NCEP) $1^{\circ} \times$ $1^{\circ}$ reanalysis data. The simulation started at 00:00 UTC, 25 June 2003 and ended at 00:00 UTC, 1 August 2003. Eight
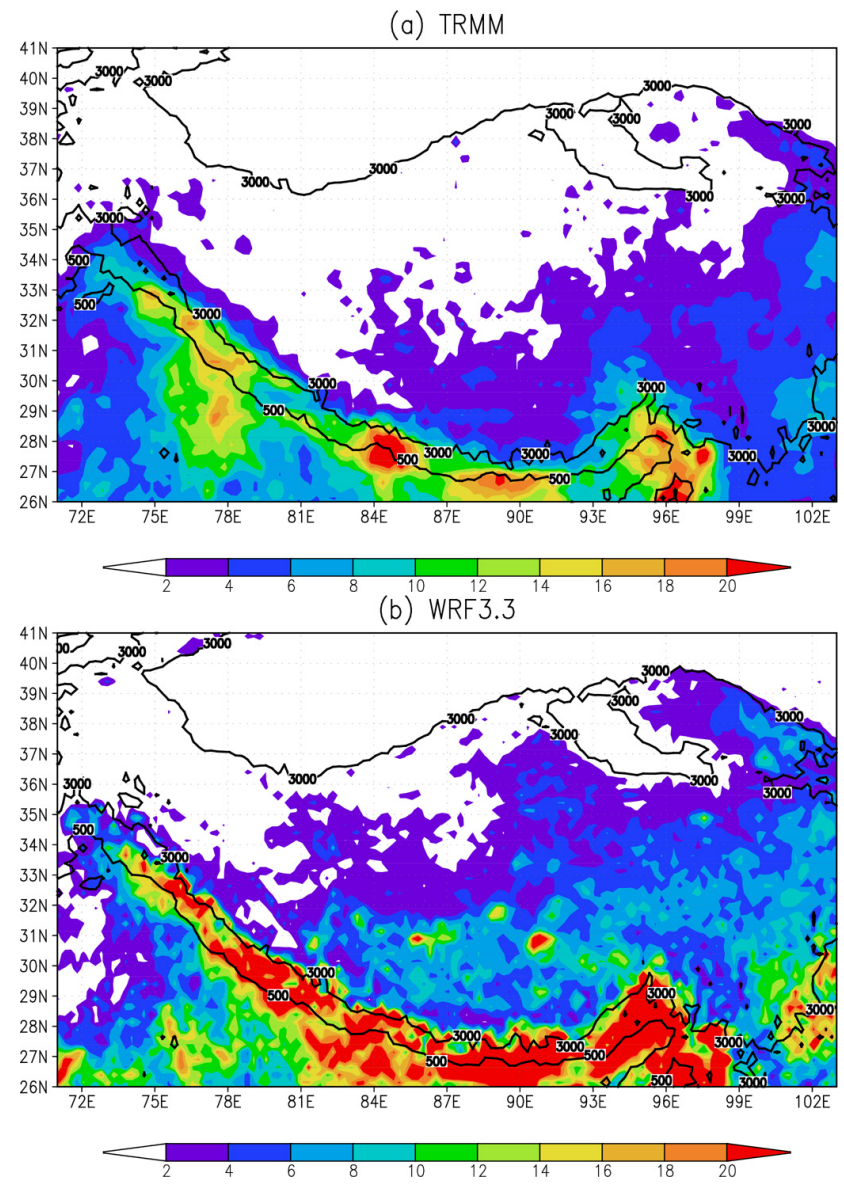

Fig. 2. Precipitation (mm day ${ }^{-1}$ ) averaged in July 2003: (a) TRMM data, (b) model simulation. Solid lines indicate the 3000 and $500 \mathrm{~m}$ topographies, respectively.

outputs from 00:00 UTC to 21:00 UTC were generated each day at $3 \mathrm{~h}$ intervals. Only simulation results in July 2003 were analysed (the first 6 days of simulation were considered as the model spin-up time). TRMM 3B42 data, which have a $0.25^{\circ} \times 0.25^{\circ}$ resolution and outputs at $3 \mathrm{~h}$ intervals from 00:00 UTC to 21:00 UTC, were used for verification.

\section{Analytical method}

Harmonic analysis (Roy and Balling, 2005) was used to examine the diurnal time series of $3 \mathrm{~h}$-accumulated rainfall averaged in July 2003 (the measurable precipitation defined was $>0.02 \mathrm{~mm} \mathrm{~h}^{-1}$ for the simulated precipitation and TRMM observation (Zhou et al., 2008).

$P=\bar{P}+\sum_{i=1}^{N / 2} A_{i} \cos \left(i \frac{2 \pi t}{N}-\varphi_{i}\right)$,

where $P$ and $\bar{P}$ are the precipitation and corresponding daily mean, respectively, $N=8$ is the number of total daily observations or outputs of the model, $t$ is the time of day, and 
(a) TRMM

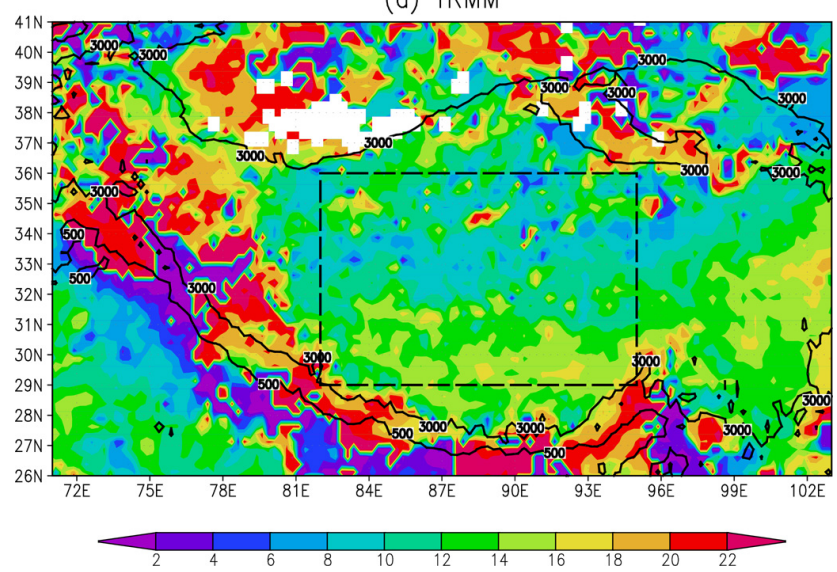

(b) WRF 3.3

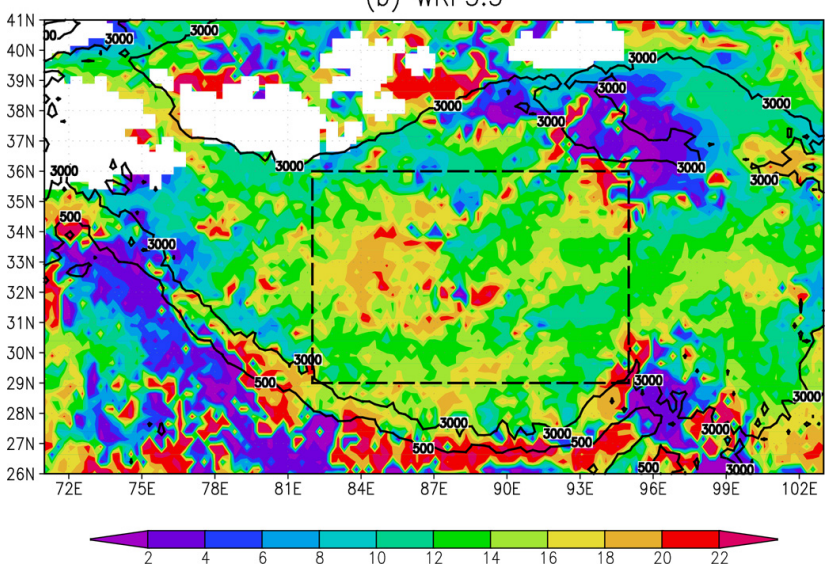

Fig. 3. Phase (UTC) of the diurnal harmonic of $3 \mathrm{~h}$ rainfall: (a) TRMM data, (b) model simulation. Solid lines indicate the 3000 and $500 \mathrm{~m}$ topographies, respectively. The dashed rectangles represent the central plateau.

(a) Central_TP: $(82-95 \mathrm{E}, 29-36 \mathrm{~N})$

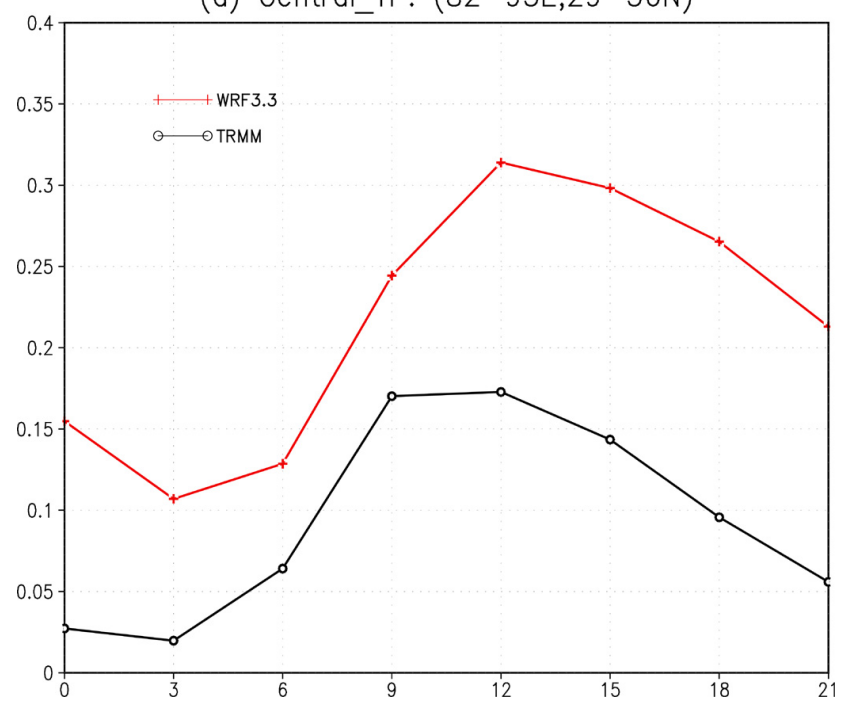

(b) Southern_edge

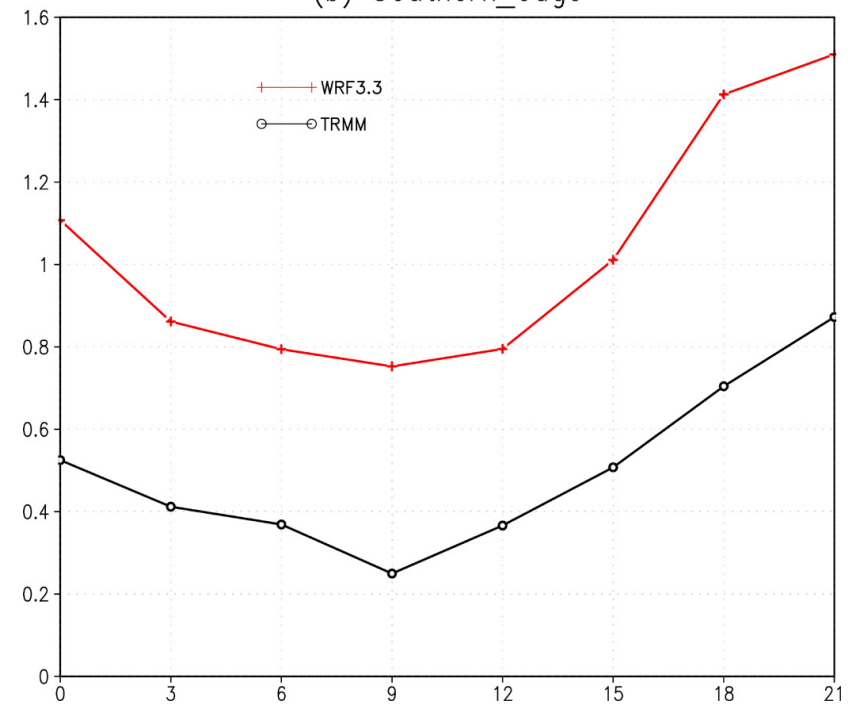

Fig. 4. Diurnal variation in precipitation $\left(\mathrm{mm} \mathrm{h}^{-1}\right)$ averaged over: (a) the central plateau, (b) the southern edge.

$A_{i}$ and $\varphi_{i}$ are the amplitude and phase of the $i$-th harmonic mode, respectively. The calculated $\varphi_{1}$ is the timing of the maximum.

\section{Results}

\subsection{Diurnal variation in precipitation}

Figure 2 shows the mean precipitation in July 2003. The precipitation descends northward (Fig. 2a). The rainfall amount is over $10 \mathrm{~mm} \mathrm{day}^{-1}$ in the southern edge of TP, but it is only about $2 \mathrm{~mm} \mathrm{day}^{-1}$ in the southeast plateau. In the vast areas of the northwest TP and the Qaidam Basin, the precipitation is less than $2 \mathrm{~mm} \mathrm{day}^{-1}$. The primary features are well simulated, including the precipitation pattern and heavy rainfall areas (Fig. 2b). However, compared with the TRMM observation, the simulated precipitation is a bit large overall. Other meteorological variables, such as the wind vector and geopotential height, are also well simulated (not shown).

The phase of the diurnal harmonic of $3 \mathrm{~h}$ rainfall in Fig. $3 \mathrm{a}$ indicates that the occurrence of the maximum precipitation has salient geographical dependence. Overall, the maximum precipitation in the central TP mostly occurs at around 12:00 UTC, equivalent to late-afternoon/evening local solar time (LST), whereas a nocturnal maximum prevails during 18:00-24:00 UTC (00:00-06:00 LST) at around the plateau periphery. The main characteristics are well captured by the simulation (Fig. 3b). Nevertheless, the simulated maximum occurs $4 \mathrm{~h}$ later than the TRMM data in some regions in the central western plateau, such as Ngari Sanai $\left(84^{\circ} \mathrm{E}, 33^{\circ} \mathrm{N}\right)$, 
(a) Daily-mean

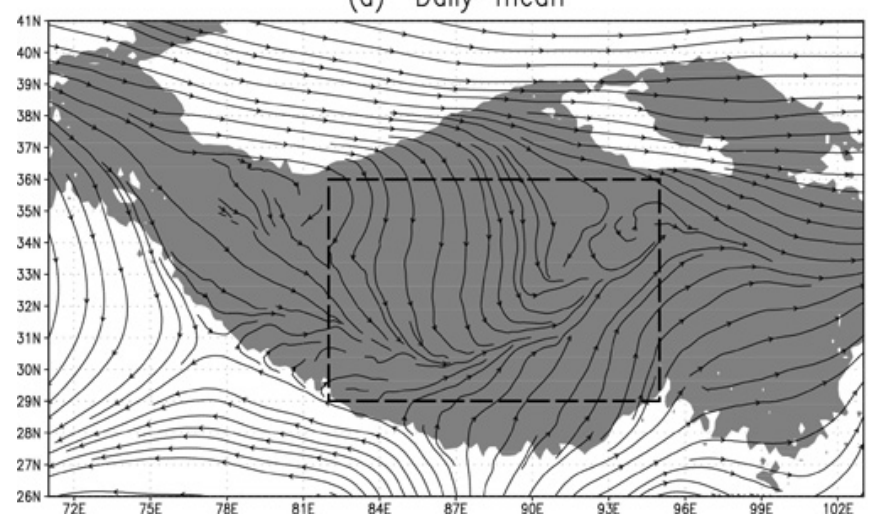

(b) Diff.(12 minus 00 UTC)

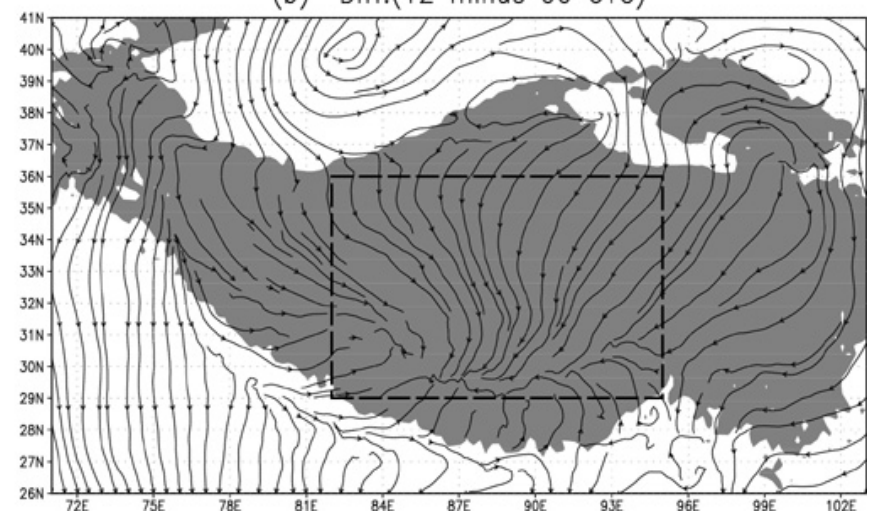

Fig. 5. $500 \mathrm{hPa}$ streamline: (a) daily-mean, (b) difference between 12:00 and 00:00 UTC. The shaded areas are above 3000 $\mathrm{m}$ and the dashed rectangles represent the central plateau.

(a) Daily-mean

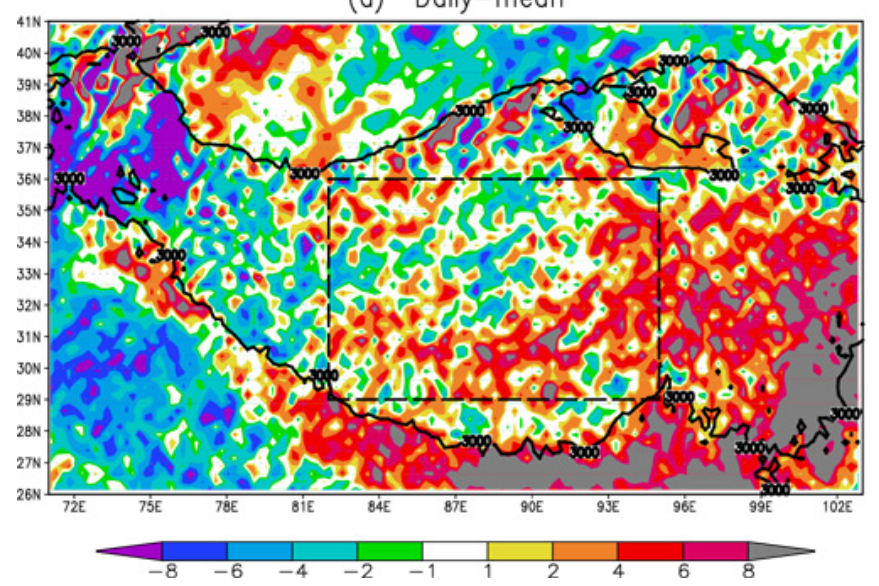

(b) Diff.(12 minus 00 UTC)

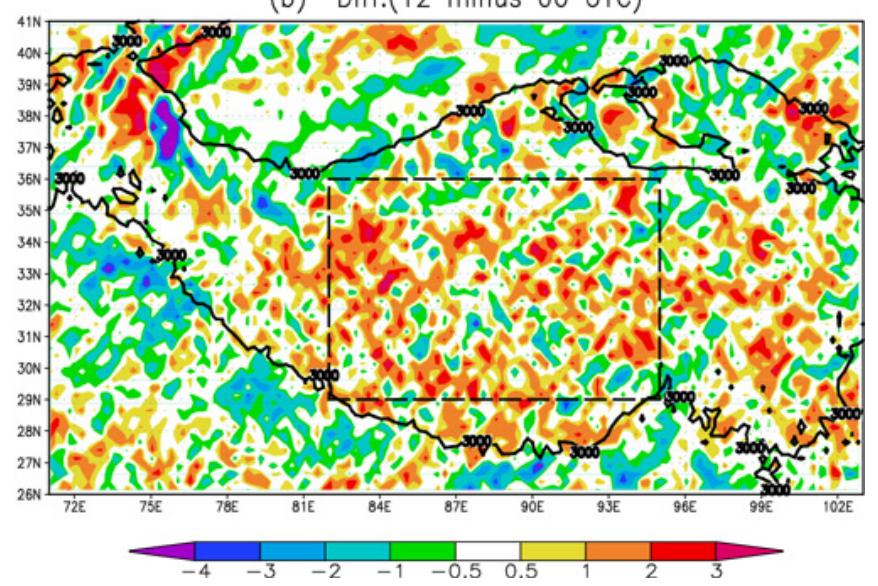

Fig. 6. $250 \mathrm{hPa}$ divergence: (a) daily mean $\left(\times 10^{-6} \mathrm{~s}^{-1}\right)$, (b) difference $\left(\times 10^{-5} \mathrm{~s}^{-1}\right)$ between 12:00 and 00:00 UTC. Solid lines indicate the $3000 \mathrm{~m}$ topography. The dashed rectangles represent the central plateau.

probably due to the simulation results being limited by very complex topography. The drought in this area may confer difficulty in detecting precipitation using satellites. In addition, the simulated amplitude of the diurnal harmonic is also comparable with the observations (figure not shown).

The simulated precipitation in the northern TP is too small to reach the measurable precipitation (Fig. 3b). Therefore, focus is mainly given on the central and southern edge of the TP. Figure 4a presents the diurnal precipitation variation averaged over the central TP $\left(82-95^{\circ} \mathrm{E}, 29-36^{\circ} \mathrm{N}\right)$. A striking diurnal variation can be seen from the TRMM data, with the minimum at 03:00 UTC, a subsequent rapid increase, the maximum at 09:00-12:00 UTC, and a slow weakening throughout the night. The model can capture well the precipitation diurnal cycle. However, the simulated magnitude is about twice as large as the TRMM data. The nocturnal maximum precipitation along the southern edge is also reasonably reproduced in the simulation (Fig. 4b). Similarly, the precipitation is overestimated. Possible mechanism to explain the nocturnal maximum in precipitation will be discussed in the following Sect. 4.4.

\subsection{Diurnal variation in circulation and thermodynamics}

The possible factors affecting the diurnal variation in summer precipitation over the TP have been explored using the high-resolution outputs of simulation. In the low troposphere over the TP $(500 \mathrm{hPa})$, a southwest-to-northeast oriented convergence zone dominates the central area (Fig. 5a). The differential streamline field (Fig. 5b) indicates stronger convergence in the late-afternoon relative to early morning in the central area, whereas the converse is evident in the southern edge. At the $250 \mathrm{hPa}$ level, the mean flow (Fig. 6a) exhibits overall divergence except in the west. In the central plateau, a stronger divergence prevails at 12:00 UTC than 00:00 UTC. In the southern edge, a convergence dominates. Taken together, the lower-level convergence and upper-level 
(a) Daily-mean

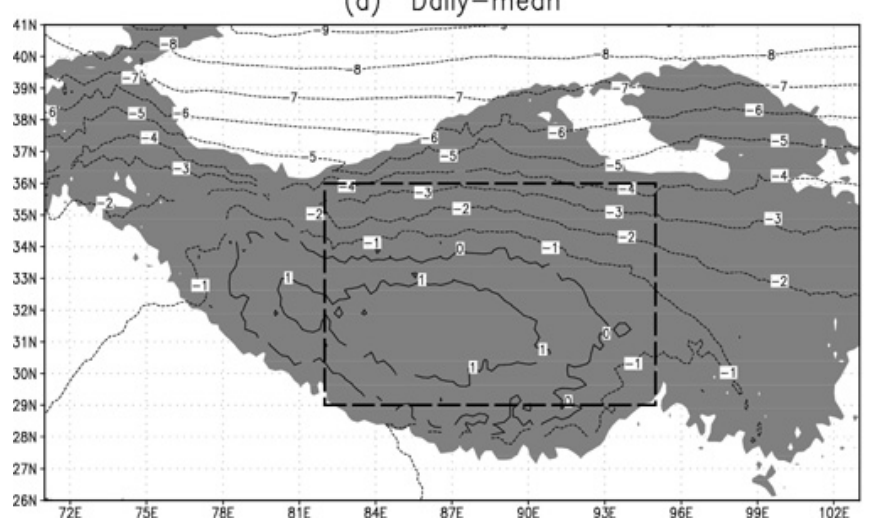

(b) Diff.(12 minus 00 UTC)

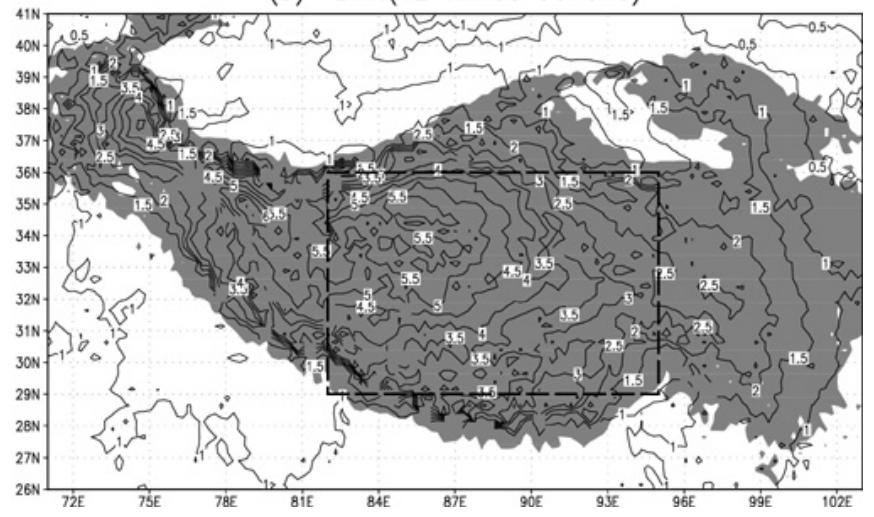

Fig. 7. $500 \mathrm{hPa}$ temperature $\left({ }^{\circ} \mathrm{C}\right)$ : (a) daily-mean, (b) difference between 12:00 and 00:00 UTC. The shaded areas are above $3000 \mathrm{~m}$, and the dashed rectangles represent the central plateau.

(a) Daily-mean

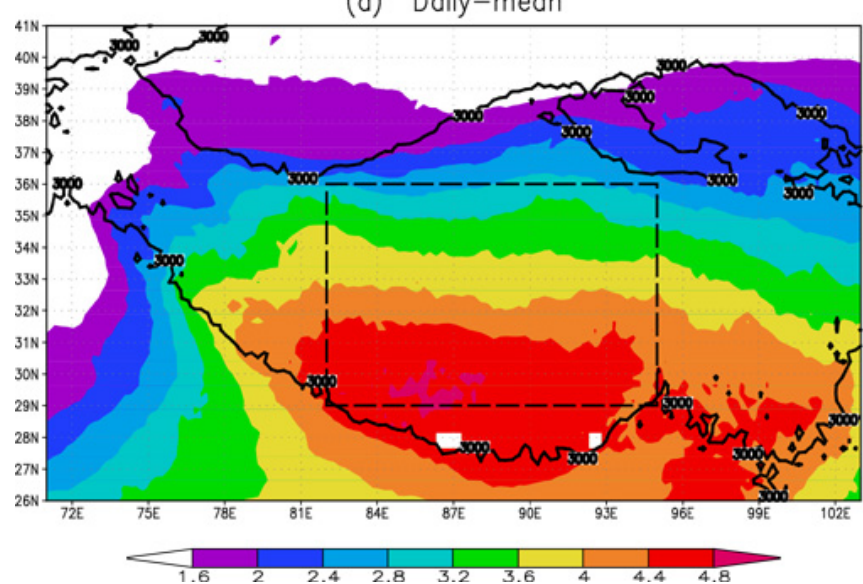

(b) Diff.(12 minus 00 UTC)

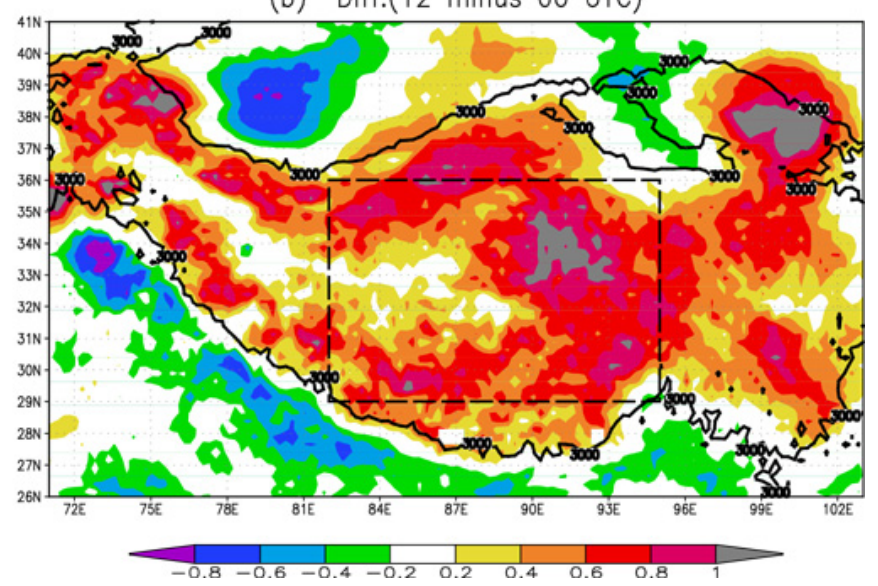

Fig. 8. $450 \mathrm{hPa}$ water vapour mixing ratio $\left(\mathrm{g} \mathrm{kg}^{-1}\right)$ : (a) daily mean, (b) difference between 12:00 and 00:00 UTC. Solid lines indicate the $3000 \mathrm{~m}$ topography. The dashed rectangles represent the central plateau.

divergence favour summer convection in the TP, and its enhancement in the late-afternoon relative to early morning in the central TP corresponds well with the precipitation diurnal cycle in the area. In contrast, the opposite flow diurnal cycle in the southern edge of the TP matches the nighttime maximum precipitation.

In summer, the TP is a huge elevated heating source (Fig. 7a) with the warmest centred in the central southern plateau. The temperature in the central part is about $4{ }^{\circ} \mathrm{C}$ higher at 12:00 UTC than 00:00 UTC (Fig. 7b), which is beneficial to convection development. Figure 8a presents the mean water vapour mixing ratio at the $450 \mathrm{hPa}$ level. The centre of moisture is located in the south and decreases toward the north. In the central part, the enhanced late-day tropospheric humidity is favourable to convection development and rainfall production, and the opposite is true in the southern edge of the TP (Fig. 8b).

\subsection{Diurnal variation in total hydrometeors}

The distribution of the vertically integrated total hydrometeors (Fig. 9a) indicates that in the central plateau, convection occurs at 06:00 UTC and greatly develops at 09:0012:00 UTC. After sunset (12:00 UTC), the convection gradually decays and almost disappears at 00:00-03:00 UTC. In the southern edge, convection appears at around 12:00 UTC, develops as time passes, reaches the maximum at 18:00 21:00 UTC, and then decreases and disappears at about 09:00 UTC. The diurnal variations in convection in the central and southern edge of the TP are consistent with the precipitation diurnal cycle. The total hydrometeors in the central plateau are almost composed of solid particles (ice, snow and graupel), whereas in the southern edge, the content of solid and liquid particles (cloud water and rain water) are roughly equal (Fig. 9b and c). 

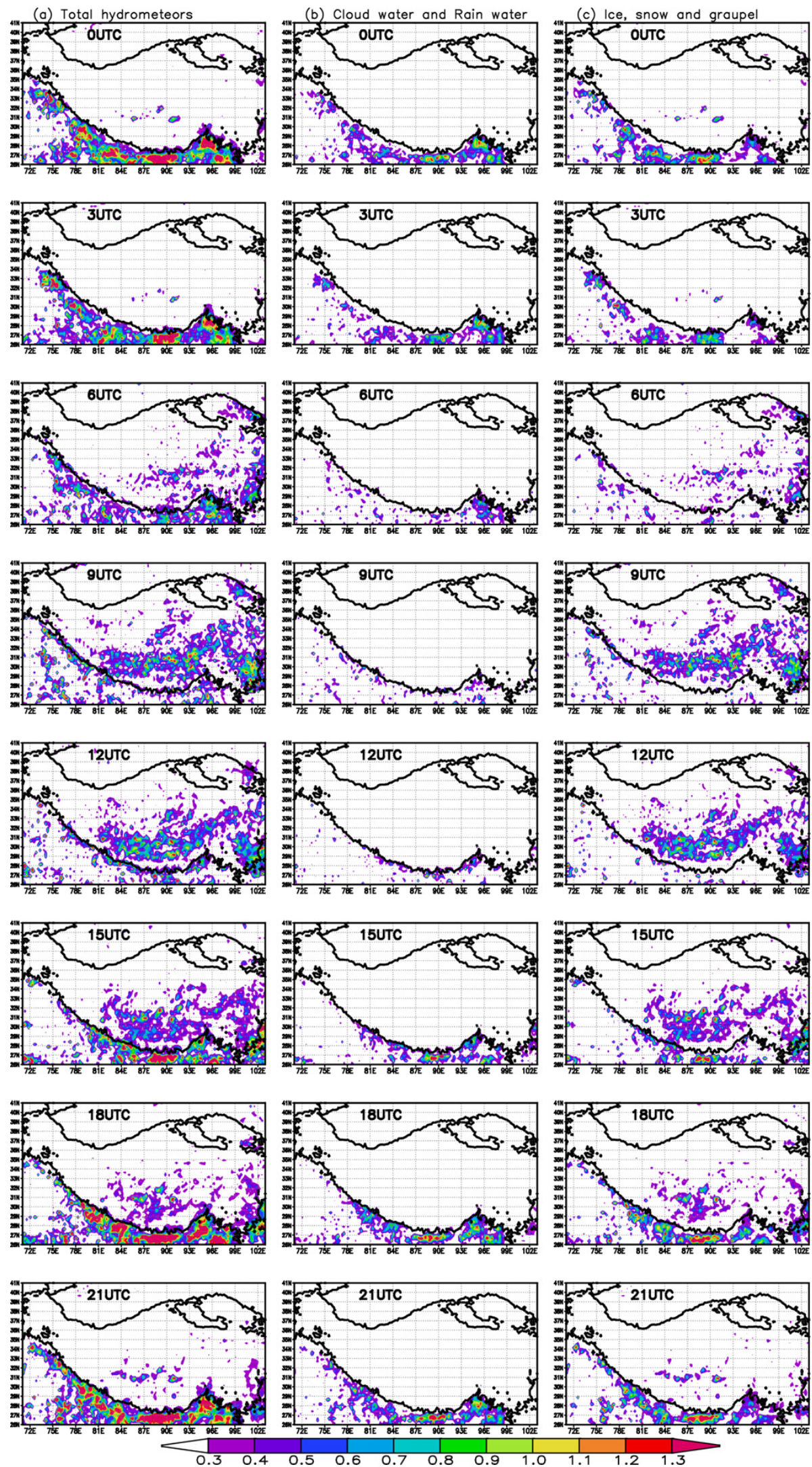

Fig. 9. Diurnal variation in vertically integrated hydrometeors $\left(\mathrm{kg} \mathrm{m}^{-2}\right)$ : (a) total hydrometeors, (b) cloud water and rain water, (c) ice, snow and graupel. Solid lines indicate the $3000 \mathrm{~m}$ topography. 

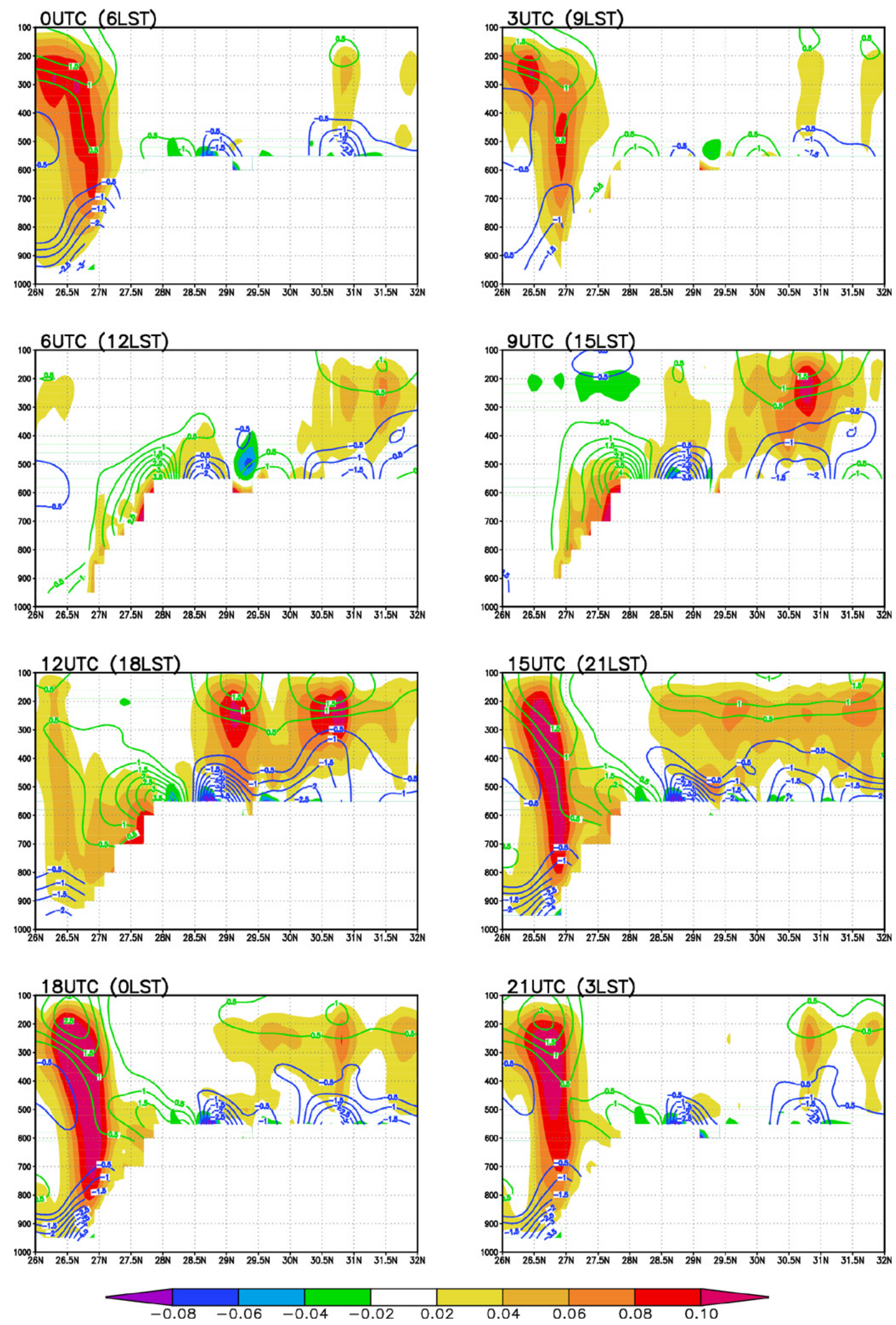

Fig. 10. Latitude-pressure cross-section averaged over $88^{\circ}-92^{\circ} \mathrm{E}$ for vertical velocity (shaded, $\mathrm{m} \mathrm{s}^{-1}$ ) and the divergence (contoured, $\times 10^{-5} \mathrm{~s}^{-1}$, where green solid indicates divergence and blue dashed indicates convergence). 

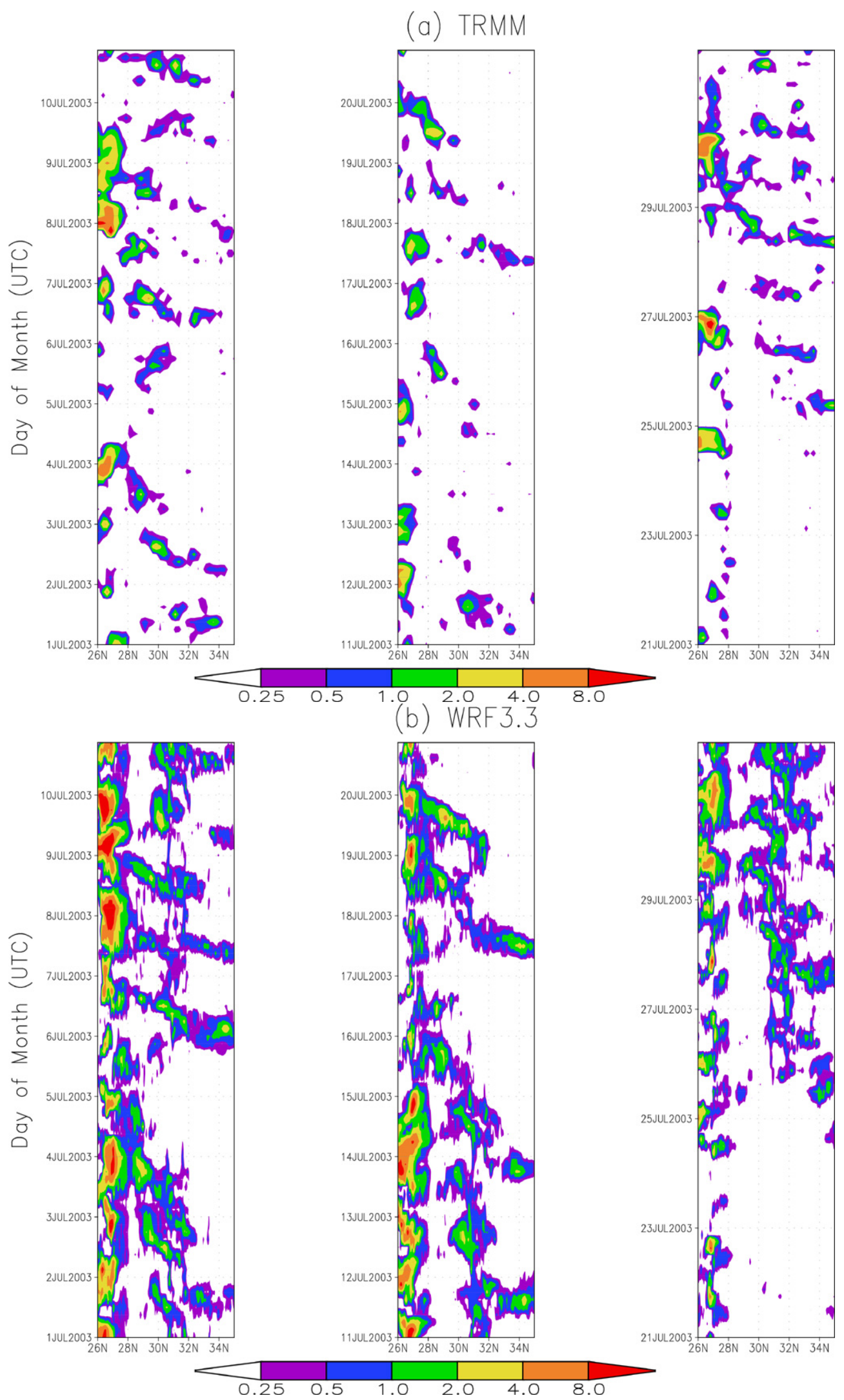

Fig. 11. The rain-rate $\left(\mathrm{mm} \mathrm{h}^{-1}\right)$ Hovmoller time-latitudinal diagram averaged from $88^{\circ}$ to $92^{\circ} \mathrm{E}$ for July 2003: (a) TRMM data, (b) model simulation. 

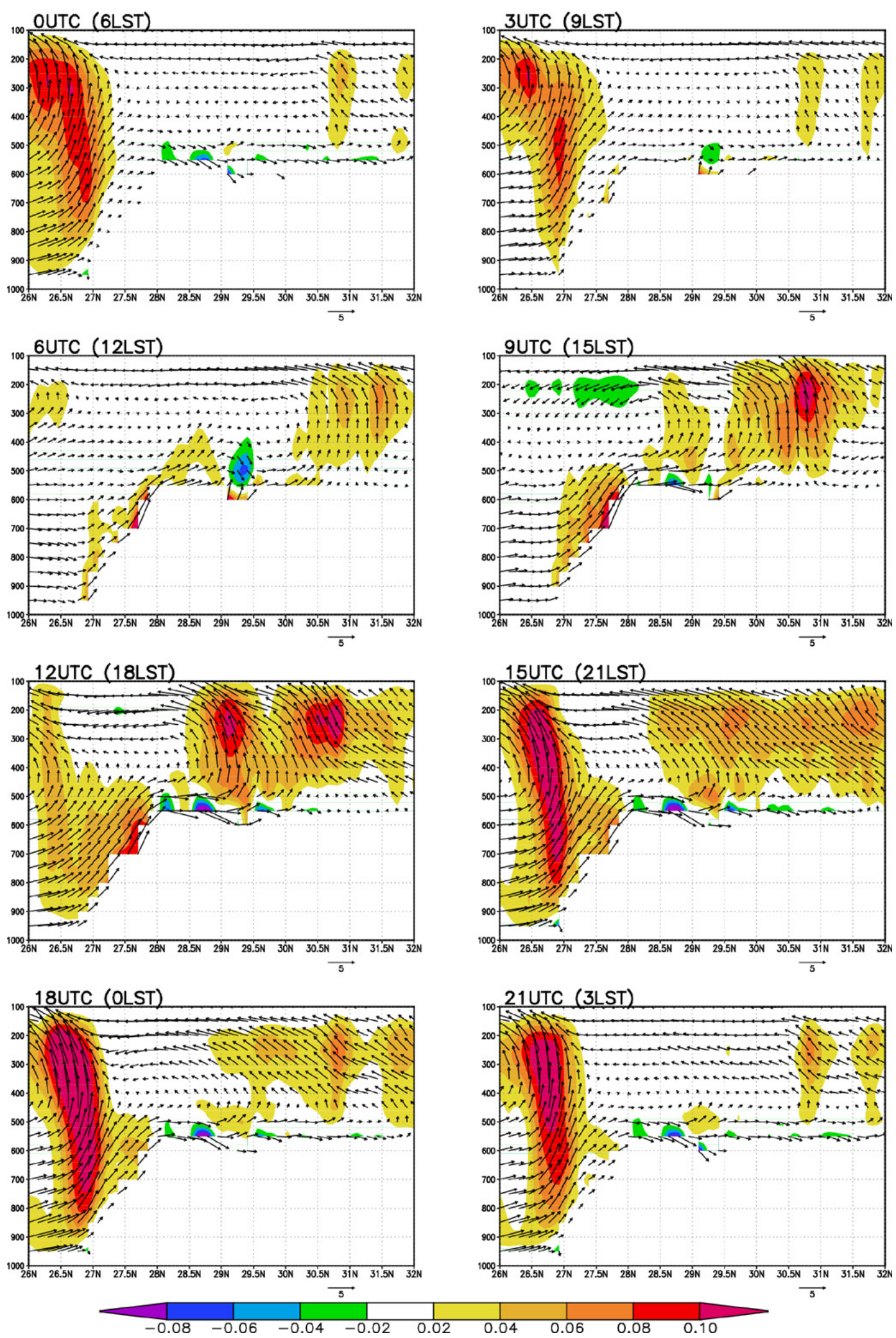

Fig. 12. Latitude-pressure cross-section averaged over $88^{\circ}-92^{\circ} \mathrm{E}$ for vertical velocity (shaded, $\mathrm{m} \mathrm{s}^{-1}$ ), and the vertical circulation vectors (v-wind and 50 times the vertical velocity). 

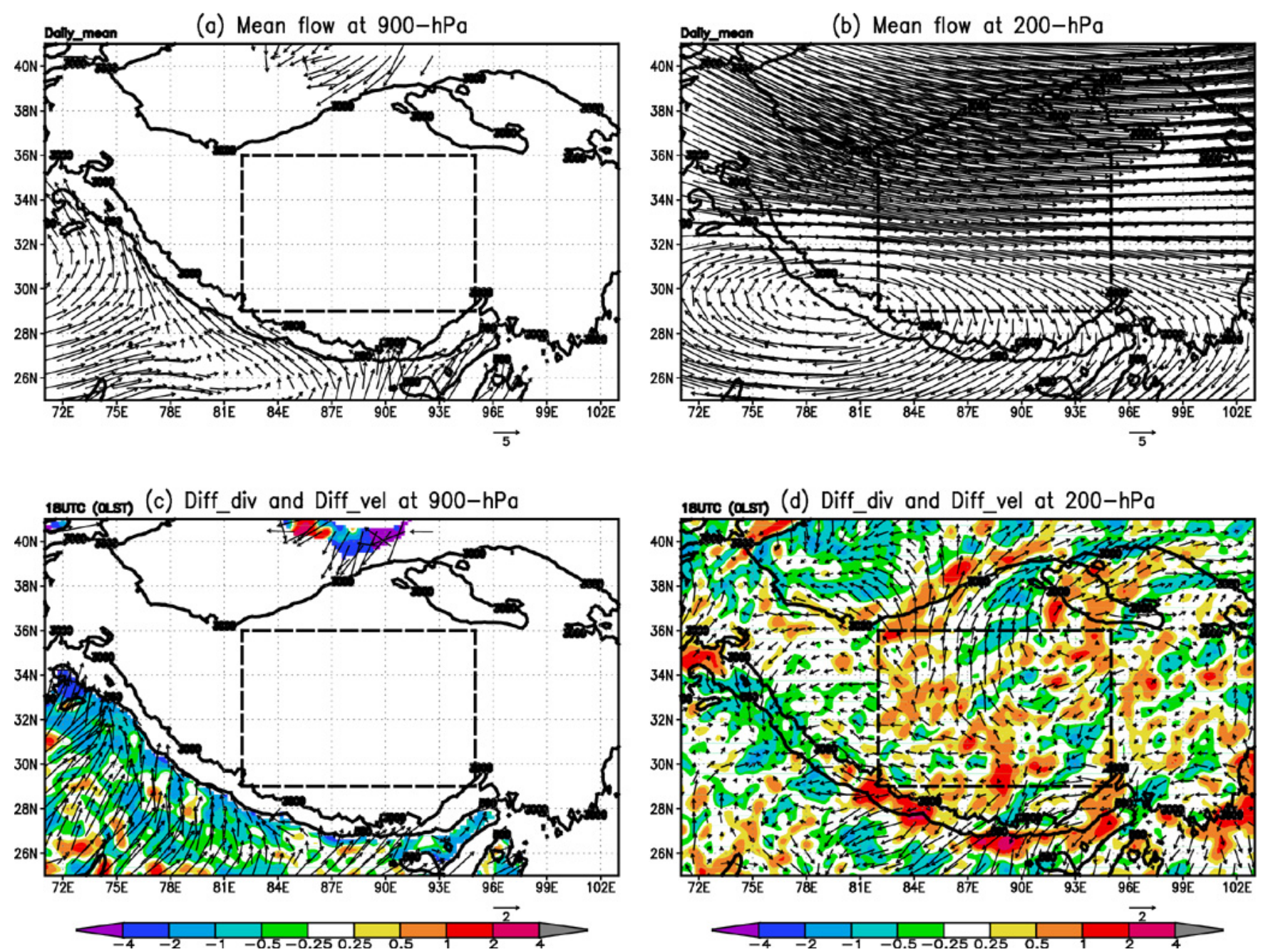

Fig. 13. Daily-mean velocity field (vectors) at levels: (a) $900 \mathrm{hPa}$, (b) $200 \mathrm{hPa}$; Diurnal variations (18:00 UTC minus daily mean) of divergence $\left(\times 10^{-5} \mathrm{~s}^{-1}\right.$, shadings) and velocity field (vectors) at levels: (c) $900 \mathrm{hPa}$, (d) $200 \mathrm{hPa}$.

\subsection{Possible mechanism responsible for the nocturnal precipitation maximum over the southern edge of TP}

Figure 10 shows a latitude-pressure cross-section of the vertical velocity averaged over $88^{\circ}-92^{\circ} \mathrm{E}$. In the day time, the surface over the TP is heated by the sun. At 06:00 UTC (12:00 LST), upward motion can be observed over the TP. This upward motion increases and reaches the maximum at 12:00 UTC (the precipitation at this time is the largest) along with the stronger surface heating. After the sunset, the upward motion over the TP decreases gradually and almost disappears at 00:00-03:00 UTC.

The Hovmöller diagram of the rain-rate (Fig. 11) indicates that the maximum precipitation at the lower part of the southern slope of the TP is separated from the precipitation in the north. Further, there is no downslope flow at the southern slope of the TP in the simulation results (Fig. 12). So the nocturnal maximum in precipitation at the lower part of the southern slope is not from the southward shift of the precipitation at the higher elevation up to the southern edge of the TP. Therefore, the mountain-plain solenoid which is widely used to explain the diurnal variation and propagation of convection (e.g., Carbone et al., 2002; He and Zhang, 2010; Wang et al., 2004) is likely to be not suitable here. Based on the model results, the authors propose a new possible mechanism responsible for this nocturnal precipitation maximum.

At 06:00 UTC (12:00 LST), the upslope flow can be seen at the upper part of the southern slope of the TP. The upslope flow increases as the solar heating continues, resulting the enhancement and expansion of the divergence over there. At 12:00 UTC (18:00 LST), this divergence along with the weak convergence at the southern foothill of the TP produces the upward motion at the lower part of the southern slope of the TP. After 12:00 UTC, the low-level convergence caused by the enhanced low-level nocturnal jet (it also brings a lot of 
warm and humid air) increases (Fig. 13a, c). Meanwhile, the upper-level divergence due to the stronger upper-level northeast flow also increased (Fig. 13b, d). In such favourable environments, the upward motion develops rapidly and reaches its maximum at 18:00 UTC (00:00 LST). After midnight, upward motion remains, but the strength decreases with the weakening of the low-level convergence and the upper-level divergence. The diurnal variation in vertical velocity corresponds well with the precipitation diurnal cycle in the central and the southern edge of the TP.

\section{Conclusions}

In this study, we investigated the diurnal variation in summer precipitation over the TP using the WRF model version 3.3 at a resolution of $3 \mathrm{~km}$. The numerical simulation was performed in July 2003 by NCEP reanalysis boundary forcing. Compared with the TRMM precipitation data, the model can well simulate the primary features of precipitation diurnal cycle in summer over the region. The maximum precipitation occurs mostly in the late-afternoon in the central plateau and usually at night in the southern edge. The simulated rainfall is about twice as large as the TRMM observation, which may be related to the horizontal resolution used in this simulation (Sato et al., 2008). A higher resolution should be considered if the computing resources are sufficient. The physical processes in the model are also far from faultless (e.g., Liu et al., 2011), leading to imperfect simulation results. Physical processes suitable for the TP need to be developed by increasing the frequency of observations over the region.

Diurnal variations in regional circulation and thermodynamic fields reflect the importance of the TP in the adjustment of regional circulation and precipitation. In the central plateau, the air has strong lower-level convergence and upper-level divergence in the late-afternoon compared with early morning. Meanwhile, the air is warmer and more humid, which is conducive to the development of convection. The maximum precipitation also occurs at this time. In contrast, the reversed-flow diurnal cycle in the southern edge of the TP coincides with the nocturnal preference for rainfall. Detailed analyses of the diurnal variations in the simulated vertical circulation and some factors such as mountain-valley flows, low-level nocturnal jet and upper-level northeast jet prompt to propose a new mechanism responsible for the nocturnal maximum precipitation over the southern edge of the TP.

Acknowledgements. The authors wish to thank two anonymous reviewers whose comments and suggestions greatly enhanced the quality of this paper. This research was jointly supported by the National Natural Science Foundation of China under Grant Nos. 41105073, 41075038, and 41175016.

Topical Editor P. M. Ruti thanks two anonymous referees for their help in evaluating this paper.

\section{References}

Bhatt, B. C. and Nakamura, K.: Characteristics of monsoon rainfall around the Himalayas revealed by TRMM precipitation radar, Mon. Weather Rev., 133, 149-165, 2005.

Carbone, R. E., Tuttle, J. D., Ahijevych, D., and Trier, S. B.: Inferences of predictability associated with warm season precipitation episodes, J. Atmos. Sci., 59, 2033-2056, 2002.

Chen, F. and Dudhia, J.: Coupling an advanced landsurfacehydrology model with the Penn State-NCAR MM5 modeling system. Part I: Model implementation and sensitivity, Mon. Weather Rev., 129, 569-585, 2001.

Chow, K. C. and Chan, J. C. L.: Diurnal variations of circulation and precipitation in the vicinity of the Tibetan Plateau in early summer, Clim. Dynam., 32, 55-73, 2009.

Dai, A.: Global precipitation and thunderstorm frequencies. Part II: Diurnal variations, J. Climate, 14, 1112-1128, 2001.

Dudhia, J.: Numerical study of convection observed during the winter monsoon experiment using a mesoscale two-dimensional model, J. Atmos. Sci., 46, 3077-3107, 1989.

Fujinami, H., Nomura, S., and Yasunari, T.: Characteristics of diurnal variations in convection and precipitation over the southern Tibetan Plateau during summer, SOLA 1, 49-52, 2005.

He, H. and Zhang, F.: Diurnal variations of warm-season precipitation over North China. Mon. Weather Rev., 138, 1017-1025, 2010.

Hirose, M. and Nakamura, K.: Spatial and diurnal variation of precipitation systems over Asia observed by the TRMM precipitation, J. Geophys. Res., 110, D05106, doi:10.1029/2004JD004815, 2005.

Hong, S. Y. and Lim, J. O. J.: The WRF Single-Moment 6-Class Microphysics Scheme (WSM6), J. Korean Meteor. Soc., 42, 129151, 2006.

Kain, J. S.: The Kain-Fritsch convective parameterization: An update, J. Appl. Meteorol., 43, 170-181, 2004.

Klemp, J. B., Skamarock, W. C., and Dudhia, J.: Conservative splitexplicit time integration methods for the compressible nonhydrostatic equations, Mon. Weather Rev., 135, 2897-2913, 2007.

Krishnamurti, T. N. and Kishtawal, C. M.: A pronounced continentalscale diurnal mode of the Asian summer monsoon, Mon. Weather Rev., 128, 462-473, 2000.

Kuo, H. L. and Qian, Y. F.: Influence of the Tibetan Plateau on cumulative and diurnal changes of weather and climate in summer, Mon. Weather Rev., 109, 2337-2356, 1981.

Liu, C., Ikeda, K., Thompson, G., Rasmussen, R., and Dudhia, J.: High-resolution simulations of wintertime precipitation in the Colorado headwaters region: sensitivity to physics parameterizations, Mon. Weather Rev., 139, 3533-3553, 2011.

Liu, L., Feng, J., Chu, R., Zhou, Y., and Ueno, K.: The diurnal variation of precipitation in Monsoon season in the Tibetan Plateau, Adv. Atmos. Sci., 19, 365-378, 2002.

Liu, X., Bai, A., and Liu, C.: Diurnal variations of summertime precipitation over the Tibetan Plateau in relation to orographicallyinduced regional circulations, Environ. Res. Lett., 4, 045203, doi:10.1088/1748-9326/4/4/045203, 2009.

Meinke, I., Roads, J., and Kanamitsu, M.: Evaluation of RSMsimulated precipitation during CEOP, J. Meteorol. Soc. Japan, 85A, 145-166, 2007.

Mlawer, E. J., Taubman, S. J., Brown, P. D., Iacono, H. J., and Clough, S. A.: Radiative transfer for inhomogeneous atmo- 
sphere: RRTM, a validated correlated-k model for the longwave, J. Geophys. Res., 102, 16663-16682, 1997.

Nesbitt, S. W. and Zipser, E. J.: The diurnal cycle of rainfall and convective intensity according to three years of TRMM measurements, J. Climate, 16, 1456-1475, 2003.

Rockel, B. and Geyer, B.: The performance of the regional climate model CLM in different climate regions, based on the example of precipitation, Meteorol. Z., 17, 487-498, 2008.

Roy, S. S. and Balling, R. C.: Analysis of diurnal patterns in winter precipitation across the conterminous United States, Mon. Weather Rev., 133, 707-711, 2005.

Sato, T., Yoshikane, T., Satoh, M., Miura, H., and Fujinami, H.: Resolution dependency of the diurnal cycle of convective clouds over the Tibetan Plateau in a mesoscale model, J. Meteorol. Soc. Japan, 86A, 17-31, 2008.
Wang, C. C., Chen G. T. J., and Carbone R. E.: A climatology of warm-season cloud patterns over East Asia based on GMS infrared brightness temperature observations. Mon. Weather Rev., 132, 1606-1629, 2004.

Yanai, M. and Li, C.: Mechanism of heating and the boundary layer over the Tibetan Plateau, Mon. Weather Rev., 122, 305-323, 1994.

Yanai, M., Li, C., and Song, Z.: Seasonal Heating of the Tibetan Plateau and its effects on the evolution of the Asian summer monsoon, J. Meteorol. Soc. Japan, 70, 319-351, 1992.

Zhou, T., Yu, R., Chen, H., Dai, A., and Pan, Y.: Summer precipitation frequency, intensity, and diurnal cycle over China: a comparison of satellite data with rain gauge observations, J. Climate, 21, 3997-4010, 2008. 